\title{
CT Guided Percutaneous Drainage of Pancreatic Abscess: A Case Report and Mini Review
}

\author{
Renato Osmenaj ${ }^{1}$, Majlinda Naço ${ }^{2}$, Alma Llukacaj*³ \\ ${ }^{1}$ Department of Imaging Sciences, HUC "Mother Theresa”, Tirana, ALBANIA \\ ${ }^{2}$ Department of Intensive Care Unit, HUC "Mother Theresa”, Tirana, ALBANIA \\ $3^{3 *}$ Department of General Surgery, HUC "Mother Theresa", Tirana, ALBANIA
}

\begin{abstract}
Pancreatic abscess (PA) has a reported incidence of 1-5\% following an episode of acute pancreatitis or pancreatic trauma, resulting from tissue necrosis, liquefaction and infection. There are an increasing number of reports on percutaneous catheter drainage $(P C D)$ of PA, being apart from the traditional surgical procedures and their expected complications. We present a case of a patient suffering from PA, treated with PCD. A good collaboration among surgeons, anesthesiologist and imaging doctors can guarantee the patient outcome.
\end{abstract}

Keywords: pancreatic abscess, fine needle aspiration, percutaneous catheter drainage, acute pancreatitis, computed tomography

\section{Introduction}

Pancreatic abscess is defined in the Atlanta Classification as "a circumscribed collection of pus, containing little or no pancreatic necrosis, which arises as a consequence of acute pancreatitis occurring more than 4 weeks after the initial attack, or pancreatic trauma ${ }^{(1)}$. The pancreatic abscess results from tissue necrosis, liquefaction, and infection. Pancreatic abscess has e reported incidence of 1-5\% following an episode of acute pancreatitis. It is claimed to have a uniformly fatal outcome in the absence of intervention. There is an abundance of literature on "pancreatic abscess". Surprisingly, however, there are few reports conforming to the definition of pancreatic abscess as described in the Atlanta classification. Although surgery has traditionally been the mainstay in the management, there are an increasing number of reports on percutaneous catheter drainage (PCD) of this dangerous complication of acute pancreatitis, dangerous not only because of considerable mortality associated, but also due to the frequent association of pancreatic abscesses with gastrointestinal fistulas, pseudo aneurysms and not uncommonly, with organ failure ${ }^{(2)}$.

This presentation describes the clinical profile, investigations performed, microbiology of the abscess and the management strategy of a case treated in the Department of the General Surgery of HUC "Mother Theresa", Tirana.

\section{Case Report}

The patient S.P., 21 years old white man, with a previous history of an abdominal automobile trauma, was recovered in the Emergency Room of General Surgery Department with the diagnosis of an acute abdomen. He had a four days history of abdominal pain, especially in the upper quadrants, back pain, vomits, abdominal distention, constipation, febrile temperature of $39.5^{\prime} \mathrm{C}$ and fatigue. According to the past medical reports, patient had surgery for the injury of several internal organs cause of the accident, among which the injury of the pancreas.

An elevated white blood cell count of $21.2 \times 10^{3} / \mathrm{mm}^{3}$ with a left shift was revealed in the blood count. An elevated level of serum amylase of $326 \mathrm{UI} / \mathrm{L}$ was present in the biochemical tests, without a compromising of the renal function and tests. A double contrast chest-abdomen CTscan was performed (Fig.1). It revealed the presence of a hypo dense area at the body and tail of the pancreas, a dilatation of the Wirsung duct, enlarged mesenteric lymph nodes and a big abscess which originates from the pancreas, extending on the right towards the Morrison space and behind the right colon and the caecum. The patient underwent the CT-guided aspiration and then the CT-guided percutaneous drain placement (Fig. 2). There was about 800 $\mathrm{ml}$ of thick, gray and non smelling pus coming out directly after the drain placement. The culture from the pus resulted positive for E.colli. Additional treatment consisted of antibiotic use (levoflaxacin $750 \mathrm{mg}$ i.v./day/once a day and metronidazol $750 \mathrm{mg}$ i.v. x 3/day for 15 days), NSAID (indomethacin suppositories $100 \mathrm{mg} \times 2 /$ day), antacids (ranitidine $100 \mathrm{mg}$ i.v. $\mathrm{x}$ 4/day), saline and dextrose infusions, electrolytes. The patient was discharged from the hospital 19 days after, in a very good condition. Meanwhile, the CT scan control was performed, which showed no abscess or fluid collection (Fig. 3)

\section{Before the drainage}




\section{International Journal of Science and Research (IJSR) \\ ISSN (Online): 2319-7064}

Index Copernicus Value (2013): 6.14 | Impact Factor (2014): 5.611

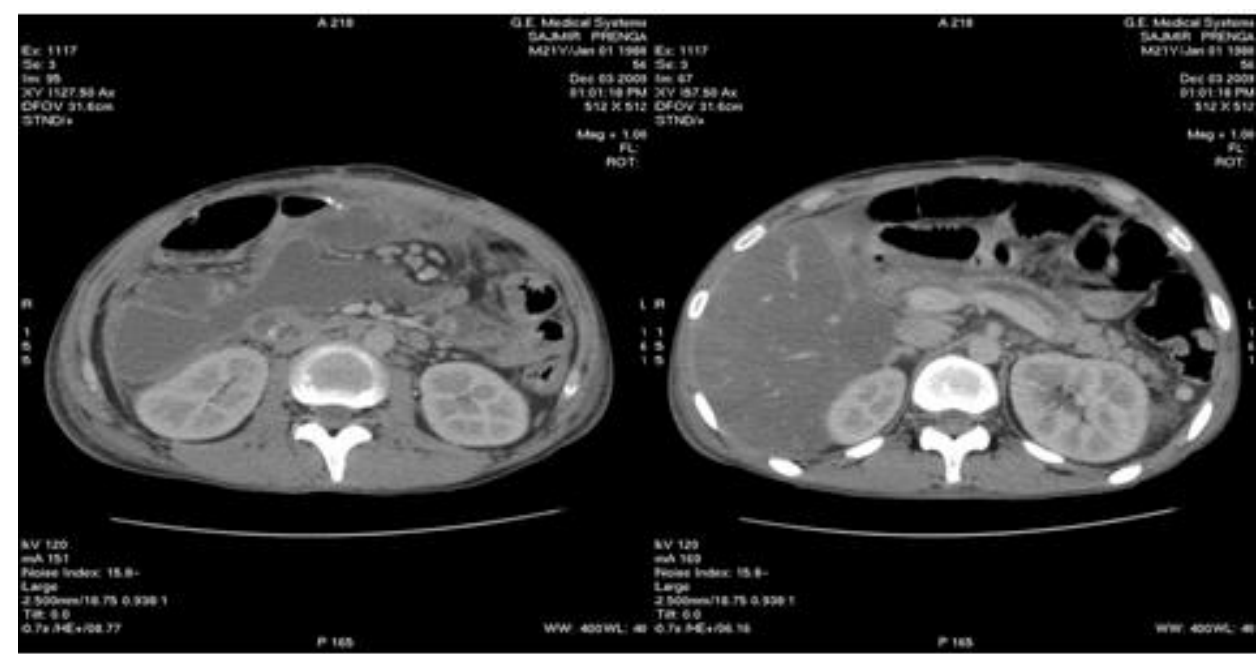

Figure 1

Percutaneous drainage procedure

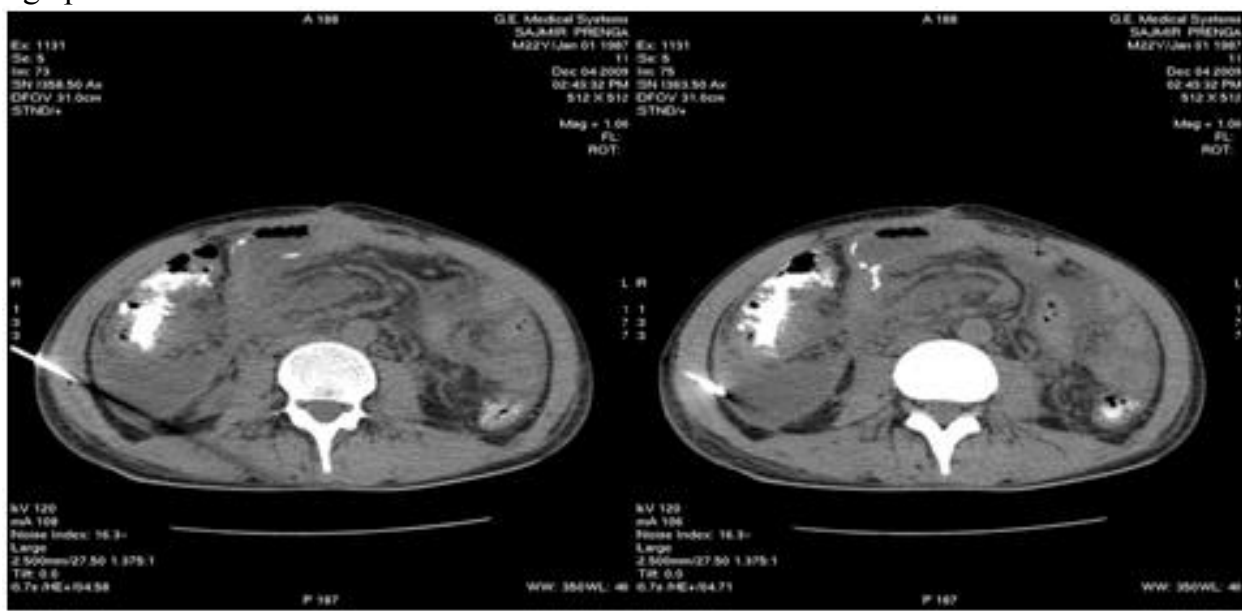

Figure 2

After the drainage

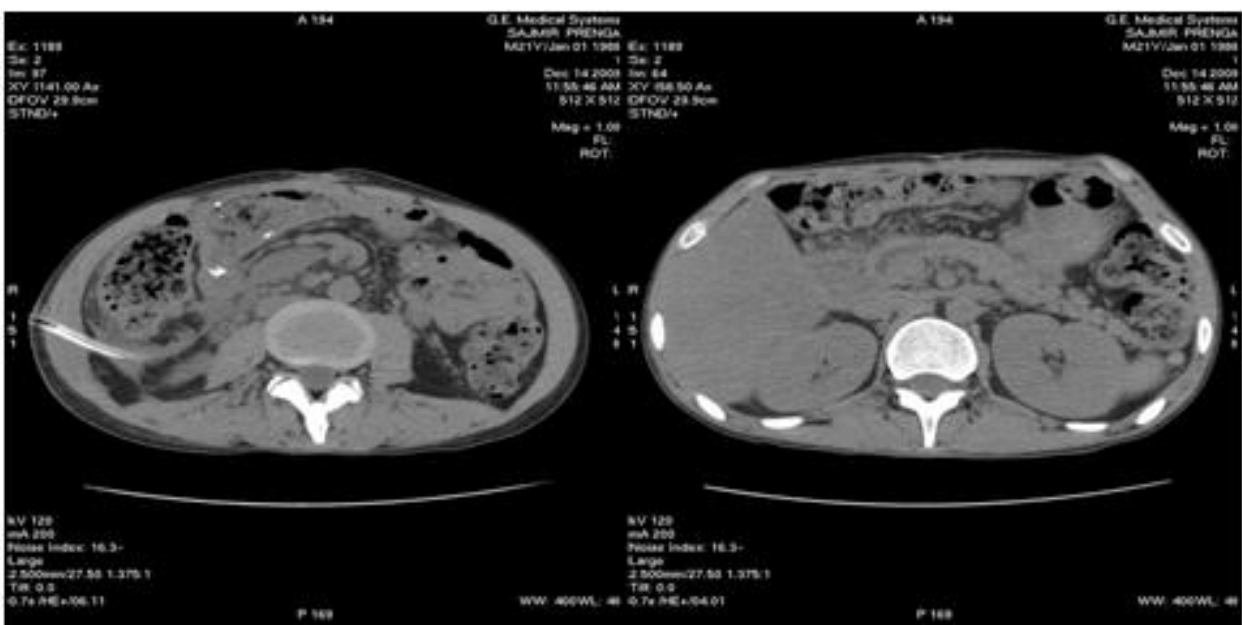

Figure 3

\section{Discussion}

\subsection{Pancreatic Abscess Definition}

There is confusion in stratifying patients into strict groups of pancreatic abscess, infected fluid collections, or infected necrosis. Many series use the terms "infected necrosis," "pancreatic abscess," "phlegmon," and "peripancreatic infection" without rigorous guidelines. The highest risk is associated with infected necrosis. Pancreatic abscess has an intermediate risk and infected pseudocyst has the lowest risk. ${ }^{(3,4)}$. An attempt to clarify this issue was made by the Atlanta group by attaching fixed definitions: thus, a pancreatic abscess is "a circumscribed intra-abdominal collection of pus, usually in proximity to the pancreas, containing little or no pancreatic necrosis which arises as a consequence of acute pancreatitis or trauma ${ }^{(5)}$. The organisms reported from cases of pancreatic abscesses

\section{Volume 4 Issue 12, December 2015}




\section{International Journal of Science and Research (IJSR) \\ ISSN (Online): 2319-7064 \\ Index Copernicus Value (2013): 6.14 | Impact Factor (2014): 5.611}

include Escherichia coli, Klebsiella species, Proteus species, Pseudomonas species, Enterobacter species, Candida species, Staphylococcus aureus, Enterococcus fecalis, Citrobacter species, Bacteroides species, Haemophilus influenza and Mycobacterium tuberculosis. ${ }^{(6,7,8,9,10)}$

\subsection{Clinical Manifestation and Radiological Findings}

The first step toward appropriate treatment of pancreatic abscesses is early accurate diagnosis. Delayed diagnosis has been identified as a major factor resulting in poor outcome and mortality. Diagnosis should be suspected when the patient begins to run a septic course, and it can be confirmed with CT and percutaneous fine needle aspiration of the pus. The cardinal signs of an abscess include fever, chills, and hypotension accompanied by a tender abdomen possibly with a growing epigastric mass. Nausea and vomiting may also occur. Leukocytosis and bacteremia strengthen the clinical diagnosis $(11,12)$. Contrast-enhanced computed tomography (CECT) is the standard imaging modality for the evaluation of acute pancreatitis and its complications ${ }^{(13)}$. A pancreatic abscess can manifest as a thick-walled lowattenuation fluid collection with gas bubbles or a poorly defined fluid collection with mixed densities/attenuation. Gas bubbles are not specific for infection, and the diagnosis of a pancreatic abscess usually requires percutaneous fineneedle aspiration to confirm the presence of pus. The diagnosis of an abscess continues to depend primarily upon a careful evaluation of the patient's clinical course together with CT studies. The presence of gas within the fluid may be an extremely valuable sign of infection ${ }^{(14)}$. The abscess may be uni- or multilocular and can spread superiorly into the mediastinum, interiorly into the transverse mesocolon, or down the retroperitoneum into the pelvis ${ }^{(11,15)}$. However, any one patient with an abscess may have only one or two of these signs $(11,12,15)$

\subsection{CT Percutaneous Drainage of Pancreatic Abscess}

Following appropriate diagnosis, and radiologic and surgical consultation, CT guided needle aspiration may be performed. In cases of abscesses that yield pus, a catheter may be placed to drain the purulent fluid. The majority of pancreatic collections are located in the lesser sac, the anterior pararenal space, or other parts of the retroperitoneum and can be drained with a catheter inserted percutaneously ${ }^{(2)}$. Patient's temperature, WBC, and drainage volume are monitored. A decrease in temperature should be expected in 24-48 hours; the WBC count should decrease within a week. The catheter may be pulled upon resolution of symptoms, normalization of vitals/WBC, decrease of abscess cavity size (as measured by repeat CT/US), and cessation of drainage. Percutaneous drainage (PCD) is effective in $40 \%$ of patients as the sole method of treatment. Studies have shown PCD of abscesses to be more effective than surgical methods, with lower mortality, complications, and recurrence ${ }^{(16)}$

\section{Conclusions}

The pancreatic abscess is a complication of Acute Pancreatitis or pancreatic trauma. It is the cause of a septic status and may be life threatening for the patient.
Percutaneous interventional therapy plays an important role in treating complications of acute and chronic pancreatitis. With the development of cross-sectional imaging and advanced interventional techniques, percutaneous drainage has become the preferred treatment for pancreatic fluid collections such as acute collections, pseudocysts and abscesses, being apart from the traditional surgical procedures and their expected complications ${ }^{(17)}$

\section{References}

[1] A clinically based classification system for acute pancreatitis. Summary of the International Symposium on Acute Pancreatitis, Atlanta, Ga, September 11 through 13, 1992.Bradley EL 3rd Arch Surg. 1993 May; 128(5):586-90.

[2] Acute pancreatitis: the role of imaging and interventional radiology.Maher MM, Lucey BC, Gervais DA, Mueller PR Cardiovasc Intervent Radiol. 2004 May-Jun; 27(3):208-25.

[3] Infections complicating severe pancreatitis. Traverso LW Infectious Dis Clin 1992; 6:601-611.[PubMed]

[4] Fine-needle aspiration of pancreatic fluid collections.; Stiles GM, Berne TV, Thommen VD, Molgarrd CP, Boswell WD. Am Surg 1990; 56:764-768. [PubMed]

[5] A clinically based classification system for acute pancreatitis.; Bradley EL III 128:586-590. Arch Surg 1993 [PubMed]

[6] Percutaneous radiological drainage of pancreatic abscess.; van Sonnenberg E, Wittich GR, Chon KS, D'Agostino HB, Casola G, Easter D, et al. AJR Am J Roentgenol 1997;168:979-84.

[7] Pancreatitis after Losartan.; Birck R, Keim V, Fiedler F, van der Woude FJ, Romeiss P. Lancet 1998;351:1178.

[8] Management of infection in acute pancreatitis. Hartwig W, Werner J, Uhl W, Buchler MW. J Hepatobiliary Pancreat Surg 2002; 9:423-8.

[9] Diagnosis\& management of acute pancreatitis. Baker S. Crit Care Resusc 2004;6:17-27.

[10] Early ERCP\& papillotomy compared with conservative treatment for acute biliary pancreatitis. Folsch UR, Nitsche R, Ludtke R, Hilgers RA, Creutzfeldt W.The German Study Group on Acute Biliary Pancreatitis. N Eng J Med 1997;336:237-42.

[11] Inflammatory masses following acute pancreatitis Warshaw AL Surg Clin North Am 1974;54:62 19.

[12] Pancreatic abscess . Miller TA, Lindenauer SM , Frey CF, Stanley JC Arch Surg 1974; 108:545-551

[13] Early detection of low enhanced pancreatic parenchyma by contrast-enhanced computed tomography predicts poor prognosis of patients with acute pancreatitis. Hirota M, Satoh K, Kikuta K, Masamune A, Kume K, Hamada S, et al.Pancreas. 2012 Oct. 41(7):1099-104.

[14] Role of percutaneous aspiration in diagnosis of pancreatic abscess. Hill. MC, Dach JL, Barkin J, et al Am J Roentgenol 1983; 141: 1035-1038

[15] Acute pancreatitis . Ranson JHC Curr Probl Surg $1979 ; 16: 5-83$

[16] Percutaneous Abscess Drainage Evan J Samett, MD; Chief Editor: Kyung J Cho, MD, FACR, FSIR more..., emedicine.medscape.com/article, May 2, 2014

[17]Does an Infected Peripancreatic Fluid Collection or Abscess Mandate Operation? Nicole B. Baril, MD,

\section{Volume 4 Issue 12, December 2015}




\section{International Journal of Science and Research (IJSR) \\ ISSN (Online): 2319-7064}

Index Copernicus Value (2013): 6.14 | Impact Factor (2014): 5.611

Philip W. Ralls, MD, Sherry M. Wren, MD, R. Rick

Selby, MD, Randall Radin, MD, Dilip Parekh, MD,

Nicolas Jabbour, MD, and Steven C. Stain, MD Ann

Surg. 2000 Mar; 231(3): 361-367.

Volume 4 Issue 12, December 2015

www.ijsr.net 